\title{
THE CONSEQUENCES OF CHRONIC PAIN IN MID-LIFE: EVIDENCE FROM THE NATIONAL CHILD DEVELOPMENT SURVEY
}

\author{
David G. Blanchflower \\ Alex Bryson \\ Working Paper 29278 \\ http://www.nber.org/papers/w29278 \\ NATIONAL BUREAU OF ECONOMIC RESEARCH \\ 1050 Massachusetts Avenue \\ Cambridge, MA 02138 \\ September 2021
}

Alex Bryson thanks the Health Foundation for funding (grant number 789112). We thank the ESRC Data Archive for access to the National Child Development Survey data. The views expressed herein are those of the authors and do not necessarily reflect the views of the National Bureau of Economic Research.

At least one co-author has disclosed additional relationships of potential relevance for this research. Further information is available online at http://www.nber.org/papers/w29278.ack

NBER working papers are circulated for discussion and comment purposes. They have not been peer-reviewed or been subject to the review by the NBER Board of Directors that accompanies official NBER publications.

(C) 2021 by David G. Blanchflower and Alex Bryson. All rights reserved. Short sections of text, not to exceed two paragraphs, may be quoted without explicit permission provided that full credit, including $\odot$ notice, is given to the source. 
The Consequences of Chronic Pain in Mid-Life: Evidence from the National Child Development Survey

David G. Blanchflower and Alex Bryson

NBER Working Paper No. 29278

September 2021

JEL No. I12,I31

\begin{abstract}
Using data from all those born in a single week in 1958 in Britain we track the consequences of short pain and chronic pain in mid-life (age 44) on health, wellbeing and labor market outcomes in later life. We examine data taken at age 50 in 2008, when the Great Recession hit and then five years later at age 55 in 2013. We find those suffering both short-term and chronic pain at age 44 continue to report pain and poor general health in their 50s. However, the associations are much stronger for those with chronic pain. Furthermore, chronic pain at age 44 is associated with a range of poor mental health outcomes, pessimism about the future and joblessness at age 55 whereas short-duration pain at age 44 is not. Uniquely, we also show that pain experienced in childhood, at ages 11 and 16, reported by a parent and a teacher respectively, collected decades earlier, predicts pain in mid-life, indicating just how persistent pain can be over the life-course.
\end{abstract}

David G. Blanchflower

Bruce V. Rauner Professor of Economics

6106 Rockefeller Hall

Dartmouth College

Hanover, NH 03755-3514

and Adam Smith School of Business, University of Glasgow

and also NBER

David.G.Blanchflower@Dartmouth.EDU

Alex Bryson

Professor of Quantitative Social Science

UCL Social Research Institute

University College London

20 Bedford Way

London WC1H 0AL

United Kingdom

a.bryson@ucl.ac.uk 


\section{Introduction}

"To live with chronic pain is to live with daily challenges around simple tasks that others take for granted. It often means being disbelieved, stigmatised for not getting better, or judged as not coping. It might mean living with poor mental health and selfesteem, absenteeism from school or work, the breakdown of relationships, and socioeconomic disadvantage. For society, the costs are staggering: low back pain is the leading cause of years lost to disability and chronic pain costs billions of dollars through health system expenditures, productivity losses, reduced quality of life, and informal care......Chronic pain is real. It deserves to be taken more seriously."

The Lancet editorial May 29 , 2021

Advances are being made in medicine in understanding the nature of chronic pain and how to treat it, as the special issue of The Lancet devoted to the issue indicates. There is also an appreciation of the problems it brings to suffers in daily life. Chronic pain is a very serious problem affecting a large number of people. Krueger (2017) found that nearly half of prime age men in the United States who are not in the labor force take pain medication on any given day; and in nearly twothirds of these cases, they take prescription pain medication. According to the National Academies of Sciences, Engineering and Medicine (2017) more than 100 million Americans suffer from chronic pain, that is, pain lasting at least three months.

We contribute to the literature by investigating links between pain experienced in mid-life and subsequent health, wellbeing and labor market outcomes among those born in Britain in a single week in 1958. Most longitudinal investigations of links between pain and subsequent health and labor market outcomes focus on short-term change captured over the space of a year, sometimes two, and are thus unable to shed any light on the longer-term effects of pain. Our data permit us to examine these longer-term relationships over a decade among people in midlife (between the ages of 44 and 55) and assess the effects of pain on a wider range of health, wellbeing and labor force participation outcomes than is ordinarily available in a single data set. The data also contain two additional aspects of pain that provide a more complete picture of its relationship to subsequent outcomes. We show that those reporting aches and pains at age 16 are significantly more likely to report pain forty years later when aged 55.

The partial associations between chronic pain and subsequent health and labor market outcomes are credibly causal since they persist even in the presence of lagged pain measured earlier in life and having controlled for parental and familial background in childhood, as well as a wide range of physical and mental health ailments reported in mid-life.

The remainder of the paper is structured as follows. Section Two reviews the literature on associations between pain, health, wellbeing and labor market outcomes. Section Three provides some context for our analysis by reporting the incidence of pain in the UK relative to other countries and identifying some of its correlates. Section Four introduces the National Child Development Survey (NCDS) data. Section Five presents results before we conclude in Section Six with a reflection on the implications of our findings. 


\section{Literature Review}

In the short-term pain can be distressing and debilitating, but it may be particularly problematic if it persists into the longer-term ("chronic" pain), and if it has consequences in the future for people's physical or mental health, their wellbeing, their labor market participation or prospects for a good quality of life. Here we review the association between pain and subsequent health, labor market participation and quality of life in turn.

\section{1: Pain and subsequent health}

A number of studies investigate predictors of chronic widespread pain in adulthood, including pain experienced in childhood. Some examine what is sometimes termed the "early pain pathway" by which common childhood symptoms like abdominal pain and headaches or migraine may be linked to subsequent pain. The empirical evidence is mixed. Using data from NCDS Jones et al. (2007) find evidence that multiple common symptoms (including abdominal pain and migraine/headaches) in childhood at ages 7,11 and 16 are associated with chronic widespread pain by age 45 . The size of the effect was not large, and only relatively few children experienced multiple symptoms, so the associated population attributable risk was low.

A study by Hotopf et al. (1998) using an earlier British population-based birth cohort study established in 1946 assessed the association between abdominal pain in childhood and subsequent physical and psychiatric health in adulthood. It found children with persistent abdominal pain were more likely to suffer psychiatric disorders in adulthood than those who did not suffer from childhood abdominal pain, but they were not especially prone to physical problems once psychiatric disorders were controlled for. ${ }^{1}$ Using the National Longitudinal Study of Adolescent to Adult Health (Add Health) Noel et al. (2016) also show that those experiencing chronic pain in adolescence subsequently report higher rates of lifetime anxiety and depressive disorders compared to individuals without a history of adolescent chronic pain.

There is compelling evidence regarding the persistence of chronic pain in adulthood from Mundal et al's (2014) large Norwegian prospective general population cohort study. They find chronic widespread pain persists 11 years later among half of those who initially reported it with poor sleep, obesity and chronic disease all predicting its persistence. Similarly, in Croft et al.’s (2003) study of consultation data from general practice records for over 10,000 women the strongest predictor of current pain was episodes of musculoskeletal illness and mental disorders 15 to 25 years earlier. The strongest predictor of head and neck pain was earlier migraine, while back pain was most strongly associated with earlier back complaints, abdominal pain and earlier intestinalrelated problems. However, chest pain and the presence of widespread pain were more strongly associated with previous mental health problems, rather than with region-specific illnesses.

\footnotetext{
${ }^{1}$ Other cohort studies focus on other predictors of chronic pain in adulthood. For instance, Pang et al. (2010) show behavioural problems in childhood among the 1958 NCDS cohort predict chronic widespread pain in adulthood. Similarly, Jones et al. (2009) examine the childhood antecedents to chronic widespread pain at age 45 in the NCDS. Using mothers' reports of their children's experiences by age 7 they find certain traumatic events, such as being hospitalised following a road traffic accident, do predict chronic widespread pain in adulthood. Jay et al. (2019) show that hardship in early adulthood is associated with increased risk of chronic widespread pain by age 68 in the 1946 British birth cohort study.
} 
Fewer studies consider the consequences of pain in mid-life for subsequent health outcomes. One of the few that does finds women reporting severe bodily pain suffer cognitive impairment 13 years later but pain did not significantly affect mortality rates (Kelleher et al., 2021). However, in their study of 6,940 individuals recruited from 29 practices across Grampian in the North-East of Scotland Torrance et al. (2010) find severe chronic pain is associated with all-cause mortality ten years later, and particularly circulatory system disease-related death.

There are some studies that question the importance of chronic pain for subsequent health outcomes. For example, in their study of 1,953 individuals, McBeth et al. (2002) find that whilst those with chronic widespread pain at baseline experienced increased levels of psychological distress at follow up 12 months later, the association was accounted for by concomitant features of chronic pain (the presence of other physical and psychosocial factors) rather than pain per se.

\section{2: Pain and subsequent labor market participation}

It is well-known that pain is associated with unemployment and economic inactivity (Krueger, 2017). Blanchflower and Bryson (2021a) show the unemployed suffer greater pain than the employed across the life-course, with pain incidence being highest among those not in the labor force (NILF) from age 30 onwards. Using data from the NCDS we analyze, VanDenKerkhof et al. (2011) find those who are unemployed at age 45 are more likely to report chronic widespread pain, while Macfarlane et al. (2008) show musculoskeletal pain at age 45 is greater among those in lower social classes. A similar cross-sectional correlation between pain and joblessness is found by Giladi et al. (2015), Johannes et al. (2010) and Landmark et al. (2013).

Recently, these studies of cross-sectional associations have been supplemented with studies using panel data which show pain leads to joblessness and that the effects are larger among those who experience frequent pain. For instance, using data from the German Socio-economic Panel (GSOEP) for the period 2002 to 2018 Piper et al. (2021) find those reporting pain 'always' are 45 percentage points more likely than those suffering no pain to be jobless a year later, were more likely to have cut their working hours if still in work, and to work below their desired number of hours. Effects were robust to controlling for life satisfaction, mental health, and employee's occupation at baseline, and persisted with the inclusion of person fixed effects accounting for unobserved fixed differences according to the reporting of pain and were apparent two years later.

Similarly, Virtanen et al. (2013) find musculoskeletal pain is associated with subsequent prolonged unemployment between age 31-42 among a small cohort of individuals in Northern Sweden. In their study of patients attending pain clinics in the Pacific Northwest of the United States, Von Korff and Dunn (2008) show a variety of pain measures predict unemployment and being unable to work six months later, while Kaspersen et al. (2015) find those in the Norwegian HUNT study with multiple musculoskeletal pain symptoms spend more time in unemployment over the subsequent 14 years, even conditioning on a wide range of other physical and psychological health problems.

\section{3: Pain and subsequent well-being}

It is well-known that happiness and subjective well-being more broadly (including life satisfaction, optimism and positive emotions) lead to better health and longevity (see Diener and Chan, 2011 for a review of the literature). However, the relationship may be bi-directional, with chronic pain 
and poor health leading to changes in subjective well-being (Steptoe et al., 2015). Reviewing the literature Eccleston (2019: 99) argues that "chronic pain can detrimentally alter natural ageing and halt personal development. Critical to this is the subjective judgement of who one is". He draws attention to qualitative research indicating that pain challenges individuals' core sense of who one is, distorting identity: “one's identity can be enmeshed so closely with pain that it becomes difficult to think of any aspect of one's life as being free of pain, including one's idea about any future” (p. 94). Sturgeon et al. (2017) identify pain as catastrophizing, and the perceived injustice in suffering pain, as factors contributing to pain-related distress and increased risk of long-term disability through maladaptive behavioral responses.

Perhaps the most robust evidence of a link between pain and subsequent subjective well-being is the paper by McNamee and Mendolia (2014). Using panel data from the first ten waves of the Household, Income and Labour Dynamics of Australia Survey (HILDA) they show chronic pain leads to lower life satisfaction, a finding that is robust to the inclusion of person fixed effects. They find some adaptation over a three-year period, though the effects of chronic pain persist.

A related literature examines the relationship between pain and sleep. A number of cross-sectional studies point to an association between pain and sleep problems. It is often assumed that the association is bi-directional with pain having a sleep-interfering property and sleep deprivation having a pain-enhancing effect. However, this has recently been challenged. In their daily process study Tang et al. (2012) use an electronic diary to record patients' self-reported sleep quality and efficiency, together with ratings of pain, mood and arousal at different times of the day, with sleep efficiency captured using actigraphy. They find pre-sleep pain was not a reliable predictor of subsequent sleep, whereas sleep quality was a consistent predictor of pain the next day.

In contrast, Nicassio et al (1992) found that, among a sample of patients diagnosed with rheumatoid arthritis prior pain predicted subsequent sleep problems, whereas sleep problems did not affect subsequent pain. There is also evidence that among individuals with acute low back pain poor sleep quality was associated with subsequent pain intensity (Alsaadi et al., 2014). The effect was large and robust to controlling for symptoms of depression. In a recent review of the literature Andersen et al. (2018) conclude that insomnia symptoms predispose individuals to chronic pain or the worsening of painful conditions, but "there are still few longitudinal studies investigating sleep disturbances as a possible pathogenic condition of chronic pain” (p. 1249).

\section{Pain Incidence in the UK and Its Correlates}

Piper, Blanchflower and Bryson (2021) report the incidence of pain in thirty-eight OECD countries from the Gallup World Polls of 2005-2020 (GWP) based on responses to the following question on pain the previous day:

Q1. Did you experience the following feelings during a lot of the day yesterday? How about physical pain? (WP68).

The UK was included in that sample and in Table 1 we report their table on mean pain incidence. The table confirms earlier findings in Blanchflower and Oswald (2019) using data from the International Social Survey Program (ISSP) 2011 showing that pain incidence was higher in the 
United States than the UK. ${ }^{2}$ In the GWP the UK has a mean rate of pain incidence of $21.1 \%$, which ranks $33^{\text {rd }}$ out of 38 OECD countries. Pain is lowest in Ireland (19.2\%) and highest in Chile (36.8\%). Piper et al. (2021: 17-18) found that in a pain regression across all OECD countries, controlling for gender, age, education, marital status, labor market status and year only Poland, Ireland and Japan had less pain than the UK.

In Table 2 we estimate four pain regressions using GWP data for the UK pooled over the period 2005-2020. In the first column we control for gender, age and year. Pain incidence is significantly higher among women and rises with age. Column 2 adds controls for education which are not available in 2005 so the sample size drops to 31492 from 35611 in column 1. Higher levels of education are associated with less pain and now there is a significant and positive time trend. The age and gender effects are similar to column 1 . The final column adds labor market status, which is only available for 2009-2020 and shows that those Out of the Labor Force (OLF) are especially in pain followed by the unemployed and those who are underemployed (in part-time employment but wanting full-time employment). Pain rises linearly with age in columns 1-3 and there is still a significant and positive time trend.

To examine pain incidence by age a little further we run a model using a complete set of year of age dummy variables. In Chart 1 a for the years 2005-2020 $(n=35,611)$ only gender and a time trend are included, and pain rises with age. In Chart 1b we add labor force status and education, which means the sample is restricted to the years 2009-2020, which are the years when the labor market variables are available on a consistent basis $(n=28,284) .{ }^{3}$ This suggests an inverted ushape in pain as found in Blanchflower (2020) for the United States using data from question Q1 above, from the Gallup US Daily Tracker, 2008-2017.

\section{The National Child Development Survey (NCDS) and its Pain Data}

The 1958 cohort follows all those born in one week in England, Scotland and Wales in 1958 (see http://www.cls.ucl.ac.uk/ncds). Participants are followed throughout their lives, with survey waves taking place at birth and then at ages 7, 11, 16, 23, 33, 42, 44, 46, 50 and 55.

The main pain data we use are taken from the Bio-Medical Survey (BMS) which was conducted when the NCDS respondents were mostly age 44 with the majority of interviews undertaken in $2003 .{ }^{4}$ The target sample comprised of 12,037 cohort members living in Scotland, England or Wales who responded to NCDS4, 5 or 6 (when they were aged 23, 33 and 42), and involved nurseinterviewers taking a number of biomedical measurements, including: near, distance and stereo vision; hearing; lung function; blood pressure and pulse, height and weight; and waist and hip. A

\footnotetext{
2 In the ISSP 2011 pain in the UK ranks third behind the US and Australia. 1. United States=34.2\%; 2. Australia $=31.7 \%$; 3. United Kingdom $=29.5 \%$; 4. Portugal $=28.0 \%$; 5. Norway $=27.8 \%$; 6. Sweden=26.6\%; 7 . Belgium=25.3\%; 8. Denmark=24.7\%; 9. Poland $=23.6 \%$; 10. Chile $=23.3 \%$; 11. Finland $=22.9 \%$; 12. France $=21.9 \%$; 13. Russia $=21.5 \%$; 14. Germany=21.1\%; 15. South Korea $=21.1 \%$; 16. Netherlands=20.4\%; 17. Israel=19.0\%; 18. Slovenia $=18.7 \%$; 19. Bulgaria=17.5\%; 20. Turkey=17.5\%; 21. Japan=17.4\%; 22. Slovak Republic=16.3\%; 23. Lithuania=14.0\%; 24. Switzerland=13.1\%; 25. Taiwan=11.9\%; 26. Philippines=11.3\%; 27. South Africa=10.9\%; 28. Croatia $=10.7 \%$; 29 . Czech Republic $=8.5 \%$

${ }^{3}$ In both charts we include the complete age range from 15-100 but only plot the data for ages 15-70.

${ }^{4}$ Fieldwork began in September 2002 and was completed at the end of March 2004The 9377 interviews were undertaken in $2002=19.0 \% ; 2003=76.1 \%$ and $2004=4.8 \%$. This meant that at the time of interview $95.2 \%$ were age 44 ; $4.5 \%$ were age 45 and $0.3 \%$ were age 46 .
} 
short mental health interview was also administered, and samples of blood and saliva were taken. Levels of co-operation with the survey were high, with some 9,400 cohort members taking part, and only a minority declining to provide samples of blood and saliva.

The appendix reports the questions used to determine pain in the BMS. Respondents were first asked whether in the prior month they had experienced an ache or pain lasting for one day or longer. If they answered in the affirmative, they were then asked if they had been aware of it for more than three months. We identify those saying they have experienced pain for at least three months who we call those in chronic pain and those who say pain lasted for less than that as being in short pain. They have means of $40.6 \%$ and $13.0 \%$ respectively. Overall, then, at age 44 around half the sample reported experiencing pain lasting one day or more.

The pain data in the BMS were validated by Macfarlane et al (2015) against those in other data files including against a UK Biobank sample of half a million ages 40-69 versus the 9377 respondents in NCDS. They found prevalence of pain as follows:

$\begin{array}{lcl}\text { Prevalence (\%) } & & \\ & \text { UK Biobank } & \text { NCDS } \\ \text { Any pain } & 62.8 & 53.3 \\ \text { Chronic pain } & 41.6 & 40.9 \\ \text { Shoulder/neck pain } & 23.5 & 20.4 \\ \text { Back pain } & 27.4 & 26.2 \\ \text { Hip pain } & 7.4 & 15.4 \\ \text { Knee pain } & 17.1 & 19.1\end{array}$

Macfarlane and co-authors found that chronic pain decreased with income and those will less education were more likely to report chronic pain. In relation to employment, chronic pain was least common among those in paid employment (39.8\%) and those doing unpaid or voluntary work (42.3\%), while four-fifths (78.9\%) of persons who were unable to work because of ill-health reported chronic pain.

We link the pain data from the BMS to the NCDS data which reports characteristics of the child at six other sweeps 2-4 (ages 11, 16 and 23) and 7-9 (ages 46, 50 and 55) and the Perinatal Mortality Study at birth in 1958, which also includes data on their parents. We also have self-reported backache data at age 55 which we use as one of our outcome measures. But as well as our measures of pain from the BMS when respondents were age 44, we also make use of pain measures a) at age 11 reported by a parent in 1969 b) at age 16 reported by the school in 1974 c) self-reported pain at age 50 in NCDS8 in 2008. In NCDS2, at age 11, a parent reported (n265) that in the past year the child had "recurrent abdominal pain"; overall $14.8 \%$ answered in the affirmative $(\mathrm{n}=14,115)$. In NCDS3 at age 16 the school representative is asked if the respondent "often complains of aches and pains" (n2317). Out of 14,276 responses, 227 or 1.6\% concur.

In NCDS8 at age fifty respondents were asked about how much bodily pain they had experienced over the prior four weeks with their answers coded into six categories from very mild to very severe. Reported pain at fifty rose almost linearly depending on the pain report at forty-four. The results were as follows $(n=7,948)$ with the percentage in the overall distribution in parentheses: 
none $=22 \%$ (28\%); very mild=35 (29); mild =47 (17); moderate=60 (17); severe=75 (6); very severe $=84$ (2). So of those at age fifty who said they had no pain, $21 \%$ reported chronic pain at age 44 . In contrast those with very severe pain at fifty, $84 \%$ said they had severe pain six years earlier.

Further, we find evidence that pain at 11 and 16 impacts chronic pain at age 44 . We find some evidence that pain at 16, 44 and 50 impacts backpain and other outcomes at age 55 including depression, the probability of working and attitudes to life and the future. We also find that chronic pain increases the probability of short sleep at age 50 .

\section{Results}

In Table 3 we report how chronic pain observed in the BMS at age 44 relates to the characteristics of these individuals in the NCDS7 interviews conducted in 2004 and 2005 at age 46. ${ }^{5}$ Of the 9792 observations on chronic pain in the BMS there were 9012 observations also in NCDS7. The table shows chronic pain was higher in females than males and highest in the raw data among the least educated, with lower incomes, renters, and the unemployed and especially so among those who were out of the labor force (OLF). Those with chronic pain also had relatively low life satisfaction scores.

\section{1: Predictors of Sample Attrition and Chronic Pain at Age 44}

In Table 4 we explore which characteristics collected at birth in the Perinatal Mortality Survey (PMS) in 1958 predict respondent attrition by the time respondents are asked the chronic pain question in the Biomedical Survey (BMS) at age 44. Results are presented in column 1 of Table 4. We find that those whose mothers were single with no husband were especially unlikely to respond to the BMS, as were those whose fathers were unskilled workers at the time of their birth.

Column 2 in Table 4 estimates the probability of suffering chronic pain at age 44 among respondents to the BMS. Perhaps surprisingly, father's social class in the year of the respondent's birth has a statistically significant impact on reports of chronic pain 44 years later. Those whose fathers had been professionals, managers and higher-level administrators when they were born were significantly less likely to report chronic pain 44 years later. The variables predicting a higher likelihood of attrition in column 1 tend to be negatively correlated with reporting chronic pain at age 44 suggesting that patterns of non-response may have downwardly biased estimates of the incidence of chronic pain in mid-life in this birth cohort. As noted earlier the BMS estimate of the incidence of chronic pain (41\%) is broadly consistent with estimates of the incidence of pain in the UK reported by Macfarlane et al (2015) above (42\%).

In the third column of Table 4 we rerun the estimates for chronic pain at age 44 but this time add the two pain variables at age 11 and 16. Doing this reduces the sample size to 7,645 as the sample consists of people who were present in NCDS2, NCDS3 and BMS and had non-missing values on the pain variables in childhood. Both measures of pain in childhood are positively and significantly associated with reporting chronic pain at age 44, confirming what other studies have found. It seems that pain is highly persistent over the life-course. The introduction of these childhood pain

\footnotetext{
${ }^{5} 80.1 \%$ of 9534 interviews for NCDS7 were conducted in 2004 and 1,896 in 2005. The characteristics are taken from NCDS7 because most are not collected at the BMS, which primarily collected biomedical data.
} 
variables increases the coefficients on father's social class at the time of the NCDS respondent's birth.

\section{2: Bodily pain at age 50 in NCDS8 \\ Respondents to NCDS8 were asked:}

How much bodily pain have you had during the past 4 weeks $(n=9810)$.

The responses were as follows - none (28.5\%); very mild (29.3\%); mild (17.2\%); moderate (17.4\%); severe (6.2\%) and very severe (1.6\%) - so eight percent of the sample said they were in severe or very severe pain.

Pain at age fifty was highly correlated with pain at age 44. Among those reporting chronic pain at age 44 in column 1 below, only 21\% had reported no pain at age 50, compared with $84 \%$ of those reporting "very severe" pain at age 50 .

$\begin{array}{lrcc} & \text { Chronic pain } & \text { No qualifications } & \text { Degree or higher } \\ \text { None } & 21 \% & 24 \% & 31 \\ \text { Very mild } & 35 \% & 21 & 35 \\ \text { Mild } & 47 \% & 18 & 17 \\ \text { Moderate } & 60 \% & 22 & 12 \\ \text { Severe } & 75 \% & 11 & 4 \\ \text { Very severe } & 84 \% & 3 & 1\end{array}$

Columns 2 and 3 show the distribution of pain at age 50 for those with no academic qualifications $(n=1690)$ versus those with a degree or higher $(n=2078)$ from an overall sample size of 9810. Education here is measured at NCDS8. Pain is higher among the less educated.

Table 5 uses linear estimation to establish the correlates of pain respondents were experiencing at age 50 . The dependent variable is coded from $1=$ never to $6=$ very severe. The variable has a mean of 2.49. In column 1 we include the chronic and short pain variables from the BMS at age 44 alongside sex and region: both pain variables are positive and highly significant, though the former has a coefficient two and a half times as large as the latter. We vary controls in the next three columns, but it is notable how stable the two coefficients are. In the second column we add controls for labor force status and education at 50. Confirming the raw data, pain is greater for those with less education, and especially high for those permanently sick or disabled. But adding controls for being disabled and less educated only reduces the chronic pain coefficient from .98 to .87.

We then add father's social class at the respondent's birth from the Perinatal Mortality Study. The sample size falls by around four hundred as some respondents to NCDS were not present in the PMS but were added subsequently. Having a father who was in an unskilled or semi-skilled occupation in 1958 raised the probability of reporting pain fifty years later. Finally, in column 4 we control for aches and pains at age 16 from NCDS3. ${ }^{6}$ The sample size falls by a further 650 ,

\footnotetext{
${ }^{6}$ In what follows we exclude the pain at age 11 variable as it is always insignificant in the presence of later in life pain variables.
} 
but the other coefficients are largely unchanged and indeed the coefficient on the chronic pain variable is the same. The age 16 pain variable is measured before any of the respondents left school and hence is exogenous to labor market experience (Micklewright, 1989). This group were one of the first to be subject to the Raising of the School Leaving Age (ROSLA) to sixteen that was implemented in 1972. Pain at sixteen raises the probability of pain thirty-four years later, confirming that the persistence of pain over time.

\section{3: Back pain at age 55 from NCDS9}

Bodily pain is not available in NCDS9 but what is available is back pain. Respondents were asked since their prior interview if they had had recurrent back ache, a prolapsed disc, sciatica or other back problems. They were then asked if they had each of these four outcomes individually. The variable was distributed across 885 respondents as follows: any $=25.7 \%$; with the means of the types as follows: recurrent back ache (20.1\%); sciatica (10.9\%); prolapsed disc (4.7\%) other back ache (7.5\%). 1154/8885 said one of them; 719 said two of them 303 said three and 85 said all four.

The table below shows the incidence (\%) of having any of these back pain symptoms according to characteristics at age 55:

$\begin{array}{llll}\text { Males } & 25.2 & \text { Higher degree } & 17.6 \\ \text { Females } & 26.1 & \text { Poor health } & 59.0 \\ \text { Workers } & 23.7 & \text { Fair health } & 41.0 \\ \text { Unemployed } & 24.8 & \text { Good health } & 27.9 \\ \text { Permanent sick } & 57.5 & \text { Very good health } & 18.1 \\ \text { Looking after family } & 33.0 & \text { Excellent health } & 11.1 \\ \text { Retired } & 21.3 & \text { Living comfortably } & 20.9 \\ \text { No qualifications } & 33.0 & \text { Doing all right } & 24.2 \\ \text { CSEs 2-5 } & 28.7 & \text { Just about getting by } & 28.7 \\ \text { GCSE } & 25.1 & \text { Finding it quite difficult } & 33.8 \\ \text { A-levels } & 24.3 & \text { Finding it very difficult } & 45.8 \\ \text { Degree } & 21.4 & & \end{array}$

So, back pain is highest among the less educated and the disabled and those who were finding it difficult to manage financially and those in poor health.

In Table 6 we explore the determinants of backache at 55 in NCDS9 for the $(0,1)$ outcome any backache in a similar way as we did above for bodily pain at age 50 by including a series of controls, including some from earlier sweeps of the survey. Column 1 includes short and chronic pain at age 44, along with controls for gender, labor force status, financial situation and education at age 55 plus father's social class when the cohort respondent was born. Pain a decade earlier is a significant predictor of back pain at 55. Chronic pain has more than twice as large an effect as short pain.

Column 2 includes dummy variables capturing the severity of pain experienced at age 50 from very mild to very severe, with none the excluded category. These dummy variables are themselves jointly significant, with more severe pain at age 50 more strongly correlated with back pain at age 
55. The size of the coefficients on chronic and short pain at age 44 decline but remain highly significant. Column 3 replaces severe pain at age 50 with aches and pains reported at age 16 . The variable is significant and positive. However, its significance declines in column $4(\mathrm{t}=1.6)$ when the severe pain at 50 is included. Of note is how similar results are in Tables 5 and 6 for bodily pain and back ache.

\section{4: Depression, emotional and psychiatric problems since the last interview}

Respondents in NCDS9 who are aged 55 are asked about their mental health and whether since the last interview five years earlier they have had depression, emotional, nervous, or psychiatric problems. Where they answer 'yes' we code them ' 1 ' on a dummy variable used as the dependent variable in the OLS regression reported in Table 7. It has a mean of .152 (n=8875).

Table 7 examines the association between depression at age 55 and the experience of chronic and short pain at age 44 and establishes this association under four different model specifications. Column 1 controls for sex only. In this model both chronic pain and short pain at age 44 are significant in predicting depression at age 55 . The effect is three-times larger for chronic pain than it is for short pain. The chronic pain effect remains robust to the introduction of additional controls in columns 2-4: although the size of the coefficient falls substantially it remains statistically significant. In contrast, the short pain effect falls to zero as soon as we introduce additional controls. The pain at age 11 and age 16 variables were excluded as they were always insignificant in these depression equations.

As noted earlier, there is a literature indicating bi-directional associations between pain and mental health. We therefore seek to isolate the independent effect of pain at age 44 on depression at age 55 having netted out any effects associated with mental health problems at age 44 . We do so by adding 8 mental health scores of various types from age 44, all of which are positive and statistically significant for mental health problems at age 55. We also condition on financial difficulties "getting by" at age 55 (where the reference category is "living comfortably"). The introduction of these variables, together with the introduction of personal controls identified in the footnote to the table, lowers the size of the chronic pain coefficient by two thirds, but it remains positive and significant. Results are very similar in column 3 when we introduce controls for father's social class when the NCDS respondents were born.

The fourth column of Table 7 introduces dummy variables capturing the severity of pain felt at age 50. This is independently positively associated with depression at age 55 and reduces the size of the coefficient for chronic pain at age 44 somewhat, though this remains sizeable and statistically significant, underscoring the degree to which chronic pain in the past continues to affect mental health a decade later. Pain at age 16 was never statistically significant and hence has been omitted.

\section{5: General Health at age 55 from NCDS9}

As we noted above chronic pain tends to be higher among those in poor health. The general health variable at age 55 is coded from poor $(=1)$ to excellent $(=5)$. In the case of those with poor health at 55 72\% said they had chronic pain at 44 compared with 25\% for those with excellent health. But how does pain affect future assessments of general health? We address this question in Table 8 which takes individuals' assessments of their general health at age 55 as the dependent variable 
and shows that chronic and short pain at 44 lowers general health at 55 . The effect is three times higher for chronic versus short pain across all four model specifications. The pain at 44 coefficients fall in size with the introduction of personal controls in column 2 but are very stable when introducing an overall mental health score at age 44 and father's social class at the cohort member's time of birth. The chronic pain variable at 44 lowers general health in column 4 even controlling for the severity of pain at age 50 . Once again, we excluded the childhood pain variables as they were insignificant.

\section{6: Work at age 55 in NCDS9}

Whilst some studies show pain leads to job loss in the short-term, there are few studies examining the association between pain and long-term consequences for employment. We address this issue in Table 9 which presents five models estimating the probability of being in paid work, whether an employee or self-employed at age 55 in NCDS9 as a function of pain experienced at age 44 in the BMS. Four-fifths $(80.1 \%)$ of those in the survey $(n=8,973)$ at age 55 were in paid work. Once again we excluded the childhood pain variables as they were insignificant.

Chronic pain at age 44 lowers the probability of being in paid work at age 55 . The effect size is similar across columns 1-3 with the introduction of controls for personal characteristics and father's social class when the respondent was born. The coefficient more than halves with the introduction of the severity of pain felt at age 50 but is nevertheless statistically significant and, with a coefficient of -0.03 , quantitatively meaningful. The effect is still apparent and statistically significant in the final column having conditioned on lagged labor force status at age 46 in NCDS7. Short pain also seems to reduce subsequent employment prospects in columns 1-3 but loses statistical significance with the addition of pain severity at age 50 .

\section{7: Attitudes about the present and the future at age 55}

If, as the literature review suggests, chronic pain can alter the way people see the world and think about their future, this may show up in models estimating attitudes at age 55. This is what we present in Table 10. We examine how people respond to three statements. The first question is "I feel full of energy these days" (n9casp4). The second is "I feel that life is full of opportunities" (n9casp5) while the third is "I feel that the future looks good for me" (n9casp5). Each of these variables are coded $4=$ often; $3=$ sometimes; $2=$ not often and $1=$ never. For each outcome we run two model specifications whose controls are identical to those appearing in columns 3 and 4 of Table 8. The mental health score at age 44 , which is taken from BMS, is also identical to the one in Table 8. It is coded 1-33 and in a third of cases the value is zero and in two thirds of cases the value is three or below. Its mean is 3.4. It is used to pick up mental health issues at age 44 so as to isolate the independent effects of pain more clearly. In all six columns its coefficient is highly statistically significant and negative. Once more we excluded the childhood pain variables as they were insignificant.

In all three cases we find chronic pain at age 44 elicits more negative attitudes at age 55 . The effects almost half in size having conditioned on the severity of pain experienced at age 50, which has its own independent negative effect. In contrast short pain is not statistically significant throughout. It is clear that chronic pain worsens attitudes more than a decade later.

5.8: Life satisfaction and Malaise scores at 46 (NCDS7) and at age 50 (NCDS8) 
We now turn to examine other well-being scores in Table 11. The first two sets of results examine the effects of pain at age 44 and pain in childhood on life satisfaction at age 46 and again at age 50. The final set of estimates in the right-hand panel of Table 11 examine unhappiness using the malaise score at 50 used in Gondek et al. (2021).

The left-hand column of Table 11 estimates a single model for responses to the question asked at age 46 in NCDS7: "how satisfied are you with the way life has turned out so far?". This variable is scored from 0-10 (where higher scores indicate higher satisfaction) with a mean of 7.57. We include father's social class when the NCDS member was born and region in NCDS7 as controls. Chronic pain and short pain at age 44 lower life satisfaction at age 46 . The chronic pain coefficient is one-and-a-half times larger than that for short pain. Remarkably, despite conditioning on pain at age 44, having aches and pains at age 16 is also associated with lower life satisfaction at age 46.

The second column uses the same life satisfaction question - "how satisfied are you with the way life has turned out so far?" but asked at age 50 in NCDS8. Again, responses are coded 0-10. The mean falls a little to 7.28 when compared to age 46, consistent with the U-shape in age found in the literature (Blanchflower, 2021). ${ }^{7}$ Once again, pain at age 44 is associated with lower life satisfaction, with chronic pain being particularly problematic, and pain in childhood continues to predict lower life satisfaction some 34 years later.

Column 3 plugs life satisfaction at age 46 into the life satisfaction at age 50 equation, essentially conditioning out the levels of life satisfaction respondents gave four years previously. This indicates a great deal of persistence in the life satisfaction responses; life satisfaction at age 46 has a large positive and highly significant coefficient and its introduction increases the adjusted rsquared in the model by .10. One might imagine that its introduction would knock out the effects of pain. Whilst this is the case for short pain at age 44 and childhood pain, chronic pain at age 44 remains negative and statistically significant, albeit with a coefficient that is a little under half the coefficient in column 2. Of note is that the pain at 16 variable is significant and negative in column 2 but becomes insignificant once life satisfaction at 46 is included in column 3 .

The malaise score at NCDS8 ( $\mathrm{n}=10781)$, is scored from zero to 9 and has a mean of 1.488 , with $44.3 \%$ of the sample scoring zero and $77.3 \%$ scoring 2 or below. It is the sum of the yes/no responses to nine variables regarding mental health at age 50 with means in parentheses:

1) feels tired most of the time (.275)

2) often feels miserable and depressed (.192)

3) often gets worried about things (.422)

4) often gets into a violent rage (.026)

5) often suddenly scared for no good reason (.084)

6) is easily upset or irritated (.254)

7 ) is constantly keyed up and jittery (.077)

8) whether every little thing gets on respondent's nerves (.079)

9 , whether respondent's heart often races like mad (.083)

\footnotetext{
${ }^{7}$ Blanchflower (2021) finds (Table 2), for example the midpoint in age in the UK using the UK Annual Population Surveys of 2016-2018 was in the mid-forties, with sample sizes of over 200,000 using life satisfaction, happiness and worthwhileness data.
} 
Results are striking. Regardless of model specification both chronic and short pain at age 44 impact malaise at 50 with chronic pain having the much larger effect. Aches and pains at 16 are also significantly positive in columns 4-6 and, even in the final column when the highly significant $(\mathrm{t}-\mathrm{stat}=24)$ and negative life satisfaction score at age 46 is included. Taken together Table 11 provides overwhelming evidence that chronic pain lowers happiness and raises unhappiness in subsequent years and even pain in childhood affects these outcomes 30 to 35 years later.

\section{9: Poor Sleep at age 50 in NCDS8 and problems falling asleep at age 44 in BMS}

Finally, Table 12 examines the effects of pain at age 44 and in childhood on hours of sleep per night at age 50 and then whether the respondent was a short sleeper (reporting sleep of less than 7 hours a night) and whether the respondent had problems trying to fall asleep in the last month. Following Blanchflower and Bryson (2021b), when we examine short sleep, we compare this to normal sleepers who get 7-9 hours a night and drop long sleepers of ten hours or more a night.

For both hours of sleep and short sleep at age 50 we run two model specifications. The first conditions only on sex and region. The second adds labor force status and education in NCDS8 and father's social class when the NCDS cohort member was born, as well as pain at age 16. Chronic and short pain at age 44 reduce hours of sleep six years later, with the former having bigger coefficients. The coefficients are relatively stable across the two model specifications. Pain in childhood has its own negative and statistically significant effect. Very similar results are found for short sleep: the probability of being a short sleeper at age 5 is increased by the experience of pain, particularly chronic pain, at age 44, as well as childhood pain at 16 .

In the far-right panel of Table 12 we estimate two equations estimating correlates of having problems falling asleep at age 44 . This is a problem reported by $36.7 \%$ of respondents $(n=10,58)$. It is apparent that both chronic pain and short pain affect contemporaneous problems sleeping, whereas childhood pain plays no significant role.

\section{Conclusions}

This paper supports the conclusion in a recent Lancet editorial that "chronic pain is real [and] deserves to be taken more seriously" (Lancet, 2021). The Lancet focuses on chronic pain, that is pain experienced over at least a three-month period. In the data we use in this study, two-fifths of those in their 40s reported suffering chronic pain. A major reason for taking chronic pain seriously is that it has sizeable and persistent effects on a whole range of health and wellbeing outcomes for people, including life expectancy.

Much of the literature examining the 'effects' of pain is either cross-sectional, or else examines short-term effects of pain using panel data tracking individuals over some months or, occasionally, a few years. Often effects are estimated for non-random sub-populations such as those who have sought treatment for pain. There are exceptions but they are rare. Our paper takes a very different approach. We take a cohort of all those born in a single week in 1958 in Britain and track the consequences of short pain and chronic pain in mid-life (between the ages of 44 and 50) and pain in childhood at ages 11 and 16 reported decades earlier by parents and teachers on health, wellbeing and labor market outcomes decades later in life (age 50-55). We examine a very broad range of outcomes in mid-life including pain, general health, depression, malaise, life satisfaction, 
energy levels, optimism, paid work, and sleep quality. Ours is a prospective study, thus avoiding the problems of potential recall biases.

We find those suffering both short-term and chronic pain at age 44 continue to report pain and poor general health in their 50s. However, the associations are much stronger for those with chronic pain. Chronic pain at age 44 is also associated with a range of poor mental health outcomes at age 55 including depression, pessimism about the future, malaise and lower life satisfaction, as well as poor general health, poor sleep, short sleep and joblessness. Pain experienced in childhood at age sixteen, prior to labor market entry, predicts pain in mid-life - indicating just how persistent pain can be over the life-course - and even lowers life satisfaction, reduces hours of sleep and increases malaise at age 50 - even when controlling for chronic pain at age 44 . We also find that pain at age 11 predicts pain at 44 controlling for pain at 16 .

We also find that social class of the respondent's mother's husband - not necessarily their father in 1958 reported at the time of the respondent's birth matters for a whole host of outcomes, including pain in later life. Those with fathers in less skilled occupations - such as semi-skilled and unskilled occupations - are less likely to respond to questions on pain years later. Those with a father with a professional, or higher administrator were more likely to respond. Given that we show that pain rises according to occupational and educational status it seems likely that the estimates we present likely understate pain years later. So, any bias in the data due to attrition likely works against finding evidence of the transmissibility of pain through life as those with higher levels of pain are more likely to attrit. Of note though is how stable our estimates are to the inclusion of different variables from various sweeps of the NCDS with somewhat different response rates and hence universes.

Whereas, as The Lancet article indicates, only now are people in the UK asking for chronic pain to be taken 'more seriously', the debate about pain and what to about it has been raging for some time in the United States. Some argue there is a pain pandemic in the United States, one which is being treated unsuccessfully through opioids (Case and Deaton, 2020a, 2020b). According to the Centers for Disease Control and Prevention the number of drug overdose deaths in the United States increased by nearly 5\% from 2018 to 2019 and has quadrupled since 1999 . Over 70\% of the 70,630 deaths in 2019 involved an opioid. ${ }^{8}$

Despite an explosion in opioid prescribing in the United States, pain has not subsided (Blanchflower and Bryson, 2021). One reason for this appears to be that opioids are relatively ineffective in tackling chronic pain. Recent studies have shown that other drugs are more effective than opioids in treating pain. For instance, Moore and Hersh (2013: 898) concluded that 325 milligrams of acetaminophen taken with 200 milligrams of ibuprofen provides better pain relief than oral opioids following wisdom tooth extraction. Blicher and Pryles (2017) come to a similar conclusion with regards to managing dental pain in general: "800mg of ibuprofen is demonstrably more effective in managing severe dental pain than other available prescription analgesics, including narcotic compounds. Furthermore, the combination of ibuprofen (Advil) and acetaminophen (Tylenol) offers greater pain relief than either medication alone and significantly more than the combination of acetaminophen and opioid medication both following endodontic treatment and third molar extraction” $(2017,56)$. Similarly, the review by Lewis et al. (2013) finds

${ }^{8}$ https://www.cdc.gov/drugoverdose/epidemic/index.html 
that non-opioid medications provided some positive global effect in treating sciatica while opioids did not.

We do not observe medication taken in our data, for the UK so our estimates of pain's effect on subsequent health, wellbeing and labor market outcomes is net of such treatments. However, our evidence on the persistence of pain across the life-course suggests efforts to counter it have not been wholly successful. We have shown that it is, in part, passed from one generation to the next, with those from lower social classes suffering most. Pain appears to be another source of intergenerational disadvantage, and one that is potentially as problematic as other aspects of social deprivation. 


\section{References}

Alsaadi, S. M., McAuley, J. H., Hush, J. M., Lo, S., Lin, C. C., Williams, C. M. and Maher, C.G. (2014), 'Poor sleep quality is strongly associated with subsequent pain intensity in patients with acute low back pain,’ Arthritis and Rheumatology, 66, 5: 1388-1394

Andersen, M. L, Araujo, P., Frange, C., and Tufik, S. (2018), 'Sleep disturbance and pain: a tale of two common problems', CHEST, 154, 5: 1249-1259.

Bell, D. N. F. and Blanchflower, D.G. (2019), 'The well-being of the overemployed and the underemployed and the rise in depression in the UK', Journal of Economic Behavior and Organization, volume 161, May: 180-196.

Blanchflower, D.G. (2020), 'Unhappiness and age', Journal of Economic Behavior and Organization, 176, August: 461-488.

Blanchflower, D. G. and Bryson, A. (2021a), 'Further decoding the mystery of American pain: the importance of work,' mimeo

Blanchflower, D. G. and Bryson, A. (2021b), 'Unemployment and sleep: evidence from the United States and Europe,' Economics and Human Biology, first online July $7^{\text {th }}$, 2021

Blanchflower, D.G. and A.J. Oswald (2019), 'Unhappiness and pain in modern America: A review essay, and further evidence, on Carol Graham's Happiness for All?', Journal of Economic Literature, June, 57(2): 385-402.

Blicher, B., and Pryles, R. L. (2017) “Managing Endodontic Pain: The Evidence against Opioids” Inside Dentistry, 13 (5): 53-58.

Case, A., and Deaton, A., (2020a). Deaths of Despair and the Future of Capitalism. Princeton University Press, Princeton, NJ.

Case, A., and Deaton, A., (2020b). 'The epidemic of despair: will America's mortality crisis spread to the rest of the world?' Foreign Affairs, 992 (Mar/Apr): 92-98

Croft, P., Lewis, M. and Hannaford, P. (2003). 'Is all chronic pain the same? A 25-year follow-up study’, Pain, 105: 309-317

Diener, E. and Chan, M. Y. (2011), 'Happy people live longer: subjective well-being contributes to health and longevity’, Applied Psychology: Health and Well-Being, 3, 1: 1-43

Eccleston, C. (2019) 'Lives lived longer: chronic pain, subjective wellbeing, and occupation', Chapter 8 in E. Wainwright (ed.) Work and Pain: A Lifespan Development Approach: 91-102, Oxford University Press 
Giladi, H., Scott, W., Shir, Y. and Sullivan, M. J. L. (2015), 'Rates and correlates of unemployment across four chronic pain diagnostic categories,' Journal of Occupational Rehabilitation, 25: 648657.

Gondek, D. R. Lacey, D.G. Blanchflower, and P. Patalay (2021), 'How is the distribution of psychological distress changing over time? Who is driving these changes? Analysis of the 1958 and 1970 British birth cohorts,' working paper.

Hotopf, M., Carr, S., Mayou, R., Wadsworth, M. and Wessely, S. (1998), 'Why do children have chronic abdominal pain, and what happens to them when they grow up? Population based cohort study,' British Medical Journal, 316: 1196-1200

Jay, M. A., Bendayan, R., Cooper, R. and Muthuri, S. G. (2019), 'Lifetime socioeconomic circumstances and chronic pain in later adulthood: findings from a British birth cohort study,' $B M J$ Open, doi:10.1136/ bmjopen-2018-024250

Johannes, C. B., Le, T. K., Zhou, X., Johnston, J. A., and Dworkin, R. H. (2010), 'The prevalence of chronic pain in United States adults: results of an internet-based survey,' Journal of Pain, 11, 11: 1230-1239.

Jones, G. T., Power, C. and Macfarlane, G. J. (2009), 'Adverse events in childhood and chronic widespread pain in adult life: Results from the 1958 British Birth Cohort Study,’ Pain, 143: 92-96

Jones, G. T., Silman, A. J., Power, C. and Macfarlane, G. J. (2007), 'Are common symptoms in childhood associated with chronic widespread body pain in adulthood? Results from the 1958 British birth cohort study,' Arthritis and Rheumatology, 56, 5: 1669-1675

Kaspersen, S. L., Pape, K., Gunnhild, A. V., Ose, S. O., Krokstad, S., Gunnell, D. and Bjorngaard, J. H. (2015), 'Health and unemployment: 14 years of follow-up on job loss in the Norwegian HUNT Study,' European Journal of Public Health, 26, 2: 312-317.

Kelleher, E., Hawley, S., Delmestri, A., Arden, N., Tracey, I. and Soni, A. (2021), 'The relationship between mid-life pain and cognitive impairment: a prospective, population-based study’, Rheumatology, 60, Supplement 1, https://doi.org/10.1093/rheumatology/keab247.120

Krueger, A. B. (2017), 'Where have all the workers gone? An inquiry into the decline of the US labor force participation rate', Brookings Pap. Econ. Act: 1-87

Lancet (2021), ‘Rethinking chronic pain’, Editorial, 397: 2023

Landmark, T., Romundstad, P., Dale, O., Borchgrevink, P. C., Vatten, L. and Kaasa, S. (2013), 'Chronic pain: one-year prevalence and associated characteristics (the HUNT pain study,' Scandinavian Journal of Pain, 4: 182-187.

Lewis, R. A., N. H. Williams, A. J. Sutton, K. Burton, N. U. Din, H. E. Matar, M.Hendry, C. J. Philips, S. Nafees, D. Fitzsimons, I. Rickard, and C. Wilkinson (2013) “Comparative Clinical 
Effectiveness of Management Strategies for Sciatica: Systematic Review and Network Metaanalyses”, Spine Journal, 15 (6): 1461-77.

Macfarlane, G. J., Beasley, M., Smith, B. H., Jones, G. T., and Macfarlane, T. V. (2015), 'Can large surveys conducted on highly selected populations provide valid information on the epidemiology of common health conditions? An analysis of UK Biobank data on musculoskeletal pain,' British Journal of Pain, 9, 4: 203-212.

Macfarlane, G. J., Norrie, G., Atherton, K., Power, C., and Jones, G. T. (2008), 'The influence of socioeconomic status on the reporting of regional and widespread musculoskeletal pain: results from the 1958 British Birth Cohort Study,' Ann Rheum Dis, 68: 1591-1595.

McBeth, J., Macfarlane, G. J., and Silman, A. J. (2002), 'Does chronic pain predict future psychological distress?', Pain, 96, 3: 239-245.

Micklewright, J. (1989), 'Choice at sixteen,' Economica, 56(221): 25-39.

Moore, P. A., and Hersh, E. V. (2013) “Combining Ibuprofen and Acetaminophen for Acute Pain Management after Third-Molar Extractions.” Journal of the American Dental Association, 144 (8): 898-908

Mundal, I., Grawe, R. W., Bjorngaard, J. H., Linaker, O. M., and Fors, E. A. (2014), 'Prevalence and long-term predictors of persistent chronic widespread pain in the general population in an 11year prospective study: the HUNT study,' BMC Musculoskeletal Disorders, 15: 213.

National Academies of Sciences, Engineering and Medicine (2017) Pain Management and the Opioid Epidemic: Balancing Societal and Individual Benefits and Risks of Prescription Opioid Use, National Academies Press, Washington (DC)

Nicassio, P. M. and Wallston, K. A. (1992), 'Longitudinal relationships among pain, sleep problems, and depression in rheumatoid arthritis,' Journal of Abnormal Psychology, 101, 3: 514520.

Noel, M., Groenewald, C. B., Beals-Erickson, S. E., Gebert, J. T., and Palermo, T. M. (2016), 'Chronic pain in adolescence and internalizing mental health disorders: a nationally representative study’, Pain, 157, 6: 1333-1338.

Pang, D., Jones, G. T., Power, C. and Macfarlane, G. J. (2010), 'Influence of childhood behaviour on the reporting of chronic widespread pain in adulthood: results from the 1958 British Birth Cohort Study,' Rheumatology, 49: 1882-1888.

Piper, A, Blanchflower, D. G. and Bryson, A. 'Does pain lead to job loss?' NBER Working Paper \#2863.

Steptoe, A., Deaton, A. and Stone, A.A. (2015), 'Subjective wellbeing, health and ageing.' The Lancet, 385, 9968: 640-648. 
Sturgeon, J. A., Ziadni, M. S., Trost, Z., Darnall, B. D. and Mackey, S. C. (2017). 'Pain catastrophizing, perceived injustice and pain intensity impair life satisfaction through differential patterns of physical and psychological disruption,' Scandinavian Journal of Pain, 17: 390-396.

Torrance, N., Elliott, A. M., Lee, A. J. and Smith, B. H. (2010), 'Severe chronic pain is associated with increased 10-year mortality. A cohort record linkage study,' European Journal of Pain, 14: 380-386.

VanDenKerkhof, E. G., Macdonald, H. M., Jones, G. T., Power, C. and Macfarlane, G. J. (2011), 'Diet, lifestyle and chronic widespread pain: results from the 1958 British Birth Cohort Study,' Pain and Research Management, 16: 87-92.

Virtanen, P., Janlert, U., and Hammarstrom, A. (2013). 'Health status and health behaviour as predictors of the occurrent of unemployment and prolonged unemployment,' Public Health, 127: pp. 4-52.

Von Korff, M. and Dunn, K. M. (2008), 'Chronic pain reconsidered,' Pain, 138: 267-276. 
Table 1. Mean pain rates, Gallup World Poll, 2005-2020 (weighted) \%.

Q1. Experienced physical pain yesterday - yes/no? (wp68)

$\begin{array}{llllll}\text { Australia } & 23.9 & \text { Hungary } & 29.7 & \text { Poland } & 19.3 \\ \text { Austria } & 21.3 & \text { Iceland } & 32.1 & \text { Portugal } & 33.6 \\ \text { Belgium } & 29.6 & \text { Ireland } & 19.2 & \text { Slovakia } & 27.4 \\ \text { Canada } & 27.9 & \text { Israel } & 29.8 & \text { Slovenia } & 24.9 \\ \text { Chile } & 36.8 & \text { Italy } & 25.2 & \text { South Korea } & 24.4 \\ \text { Colombia } & 30.5 & \text { Japan } & 19.7 & \text { Spain } & 29.3 \\ \text { Czech Republic } & 24.1 & \text { Latvia } & 22.9 & \text { Sweden } & 21.5 \\ \text { Denmark } & 24.7 & \text { Lithuania } & 24.2 & \text { Switzerland } & 23.6 \\ \text { Estonia } & 20.6 & \text { Luxembourg } & 25.8 & \text { Turkey } & 22.6 \\ \text { Finland } & 23.7 & \text { Mexico } & 28.4 & \text { United Kingdom } & 21.1 \\ \text { France } & 29.3 & \text { Netherlands } & 20.9 & \text { United States } & 28.3 \\ \text { Germany } & 22.5 & \text { New Zealand } & 23.0 & \text { Total } & 25.1 \\ \text { Greece } & 28.3 & \text { Norway } & 22.5 & & \end{array}$

Source: Piper, Blanchflower and Bryson (2021) 
Table 2. UK pain regression in Gallup World Poll, 2005-2020 (OLS)

\begin{tabular}{lccc} 
& $2005-2020$ & $2007-2020$ & $2009-2020$ \\
$25-29$ & $-.0051(0.40)$ & $.0068(0.50)$ & $.0393(2.72)$ \\
$30-34$ & $.0035(0.30)$ & $.0238(1.92)$ & $.0669(5.09)$ \\
$35-39$ & $.0103(0.93)$ & $.0276(2.28)$ & $.0682(5.32)$ \\
$40-44$ & $.0285(2.69)$ & $.0407(3.59)$ & $.0853(7.06)$ \\
$45-49$ & $.0218(2.06)$ & $.0312(2.75)$ & $.0772(6.39)$ \\
$50-54$ & $.0644(6.11)$ & $.0757(6.74)$ & $.1123(9.40)$ \\
$55-59$ & $.0871(8.18)$ & $.0905(7.97)$ & $.1200(10.02)$ \\
$60-64$ & $.1008(9.46)$ & $.1048(9.22)$ & $.0983(8.18)$ \\
$65-69$ & $.1019(9.31)$ & $.0999(8.59)$ & $.0575(4.60)$ \\
$70+$ & $.1512(15.70)$ & $.1474(14.28)$ & $.0971(8.54)$ \\
Male & $-.0235(5.44)$ & $-.0205(4.46)$ & $-.0057(1.16)$ \\
Year & $.0010(1.37)$ & $.0018(2.22)$ & $.0054(5.89)$ \\
Secondary & & $-.0443(5.24)$ & $-.0330(3.85)$ \\
College & & $-.0967(11.02)$ & $-.0717(8.02)$ \\
Self-employed & & & $.0238(2.37)$ \\
PT & & & $.0280(3.18)$ \\
Unemployed & & & $.0641(4.79)$ \\
PT wants FT & & & $.0555(4.52)$ \\
OLF & & & $.1528(22.05)$ \\
\multicolumn{1}{l}{ Constant } & -1.8224 & & -10.6684 \\
$\mathrm{~N}$ & 35,611 & 3.3867 & .0420 \\
Adjusted R ${ }^{2}$ & .0177 & .0227 &
\end{tabular}

Equations also include controls for education don't know and not answered. Excluded categories employee and age 15-24 
Table 3. Chronic Pain in BMS (age 44) and Characteristics in NCDS7 (age 46)

$\begin{array}{llll}\text { All } & 40.6 & \text { Income }<50 \mathrm{k} & 41.8 \\ \text { Male } & 40.1 & \text { Income }>50 \mathrm{k} & 35.4 \\ \text { Female } & 41.1 & \text { No qualifications } & 48.3 \\ \text { Single } & 40.9 & \text { Bad O-levels } & 44.4 \\ \text { Married first } & 39.0 & \text { Good O-level, 1 A level } & 39.6 \\ \text { Remarried } & 43.6 & \text { 2 or more } & 38.6 \\ \text { Separated } & 38.9 & \text { Sub-degree } & 41.1 \\ \text { Divorced } & 44.5 & \text { Degree } & 35.5 \\ \text { Widowed } & 35.6 & \text { Higher degree } & 27.8 \\ \text { Own outright } & 39.1 & \text { Excellent health } & 27.9 \\ \text { Mortgage } & 39.7 & \text { Good health } & 39.2 \\ \text { Renter } & 49.3 & \text { Fair health } & 57.5 \\ \text { Worker } & 38.4 & \text { Poor health } & 68.2 \\ \text { Unemployed } & 51.4 & \text { Very poor health } & 77.7 \\ \text { OLF } & 58.8 & \text { Life satisfaction score } & 7.40 \\ \text { Income missing } & 43.2 & \text { Non chronic pain life score } & 7.18\end{array}$


Table 4. Attrition and Chronic Pain in the BMS (OLS), 2002-2004

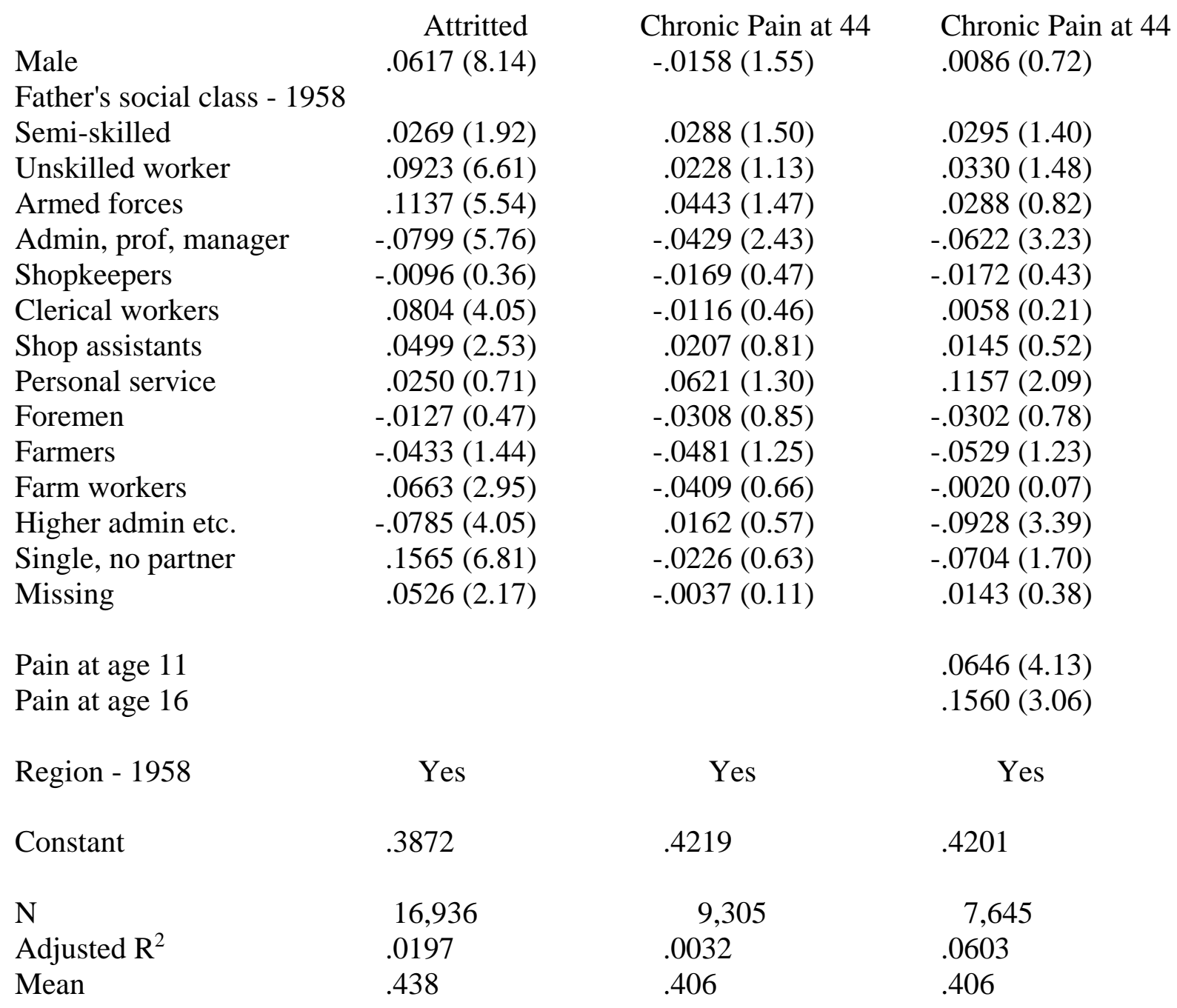

Region is in the 1958 PMS. T-statistics in parentheses. 
Table 5. Bodily pain in NCDS8 at age 50 (OLS)

\begin{tabular}{|c|c|c|c|c|}
\hline Chronic pain at 44 & .9779 (33.61) & $.8722(30.60)$ & .8790 (30.11) & $.8790(28.87)$ \\
\hline Short pain at 44 & $3855(9.14)$ & $.3779(9.28)$ & $.3751(9.01)$ & $.3770(8.67)$ \\
\hline Male & $-.1913(7.06)$ & $-.1718(5.84)$ & $-.1703(5.65)$ & $-.1598(5.08)$ \\
\hline Aches \& pains at 16 & & & & .4675 (3.76) \\
\hline PT employee & & $.0208(0.53)$ & $.0160(0.40)$ & $.0297(0.70)$ \\
\hline FT self-employed & & $-.0081(0.18)$ & $-.0224(0.48)$ & $-.0075(0.16)$ \\
\hline PT self-employed & & $.0419(0.50)$ & $.0629(0.73)$ & $.0771(0.84)$ \\
\hline Unemployed & & $.0764(0.95)$ & $.0561(0.67)$ & $.1201(1.35)$ \\
\hline FT education & & $-.3293(1.09)$ & $-.4312(1.33)$ & $-.4824(1.44)$ \\
\hline Govt. scheme & & $-.1393(0.12)$ & $-2156(0.19)$ & $-.2079(0.18)$ \\
\hline Temporarily sick/disabled & & $.5714(3.30)$ & $.5512(3.15)$ & .5759 (3.07) \\
\hline Permanently sick/disabled & & $1.6008(21.35)$ & $1.5754(20.81)$ & $1.5768(20.14)$ \\
\hline Looking after home & & $.2394(3.67)$ & $.1733(2.60)$ & 1346 (1.93) \\
\hline Wholly retired & & $.5463(3.58)$ & $.5194(3.26)$ & .5409 (3.32) \\
\hline Other & & $-.1574(1.09)$ & $-1469(0.99)$ & -1989 (1.27) \\
\hline GCSE D-E & & $-.2567(0.31)$ & $-.2662(0.32)$ & $-.2254(0.28)$ \\
\hline Other Scottish Quals & & $-.1218(2.46)$ & $-.1079(2.13)$ & $-.1104(2.08)$ \\
\hline GCSE A-C & & $-.1852(4.46)$ & $-.1735(4.05)$ & $-.1490(3.33)$ \\
\hline 2/AS Levels or 1 A Level & & $-.5261(2.91)$ & $-.5558(2.96)$ & $-.5011(2.58)$ \\
\hline 2+ A Levels & & $-.2949(5.23)$ & $-.2700(4.59)$ & $-.2661(4.30)$ \\
\hline Diploma & & $-.2290(3.37)$ & $-.2169(3.10)$ & $-.1559(2.13)$ \\
\hline Degree & & $-.3051(6.50)$ & $-.2487(5.00)$ & $-.2250(4.32)$ \\
\hline Higher Degree & & $-.3586(4.92)$ & $-.3198(4.14)$ & $-.3102(3.83)$ \\
\hline \multicolumn{5}{|l|}{ Father's social class at 0} \\
\hline Semi-skilled & & & $.0674(1.32)$ & $.0715(1.36)$ \\
\hline Unskilled worker & & & .0867 (1.57) & 1059 (1.86) \\
\hline Armed forces & & & $-.0615(0.77)$ & $-.0533(0.65)$ \\
\hline Admin, prof, manager & & & $-.0436(0.94)$ & $-.0798(1.64)$ \\
\hline Shopkeepers & & & $-.1901(2.08)$ & $-.1896(2.00)$ \\
\hline Clerical workers & & & $-.0450(0.69)$ & $-.0104(0.15)$ \\
\hline Shop assistants & & & $-.1252(1.86)$ & $-.1306(1.86)$ \\
\hline Personal service & & & $-.0896(0.69)$ & $-.1208(0.86)$ \\
\hline Foremen & & & $-.2509(2.56)$ & $-.2282(2.25)$ \\
\hline Farmers & & & $.0507(0.50)$ & $.0759(0.71)$ \\
\hline Farm workers & & & $.0182(0.24)$ & $-.0141(0.18)$ \\
\hline Higher admin etc. & & & $-.0635(0.98)$ & $-.0223(0.33)$ \\
\hline Single, no partner & & & $-.1103(1.13)$ & $-.1171(1.14)$ \\
\hline Region at 50 & Ye & Yes & Yes & Yes \\
\hline Father's social class at 0 & No & No & Yes & Yes \\
\hline Constant & 2.1886 & 2.3211 & 2.2998 & 2.2644 \\
\hline Adjusted $\mathrm{R}^{2}$ & 1309 & 1910 & 1940 & 1983 \\
\hline $\mathrm{N}$ & 7,948 & 7,948 & 7,570 & 6,920 \\
\hline
\end{tabular}

Notes: personal controls are labor force status and education in NCDS8. Pain at age 16 is from NCDS3 (n2317) student 'often complains of aches or pains? yes/no' reported by teacher/school - mean=.016. Excluded categories are: FT employee; no qualifications and skilled worker. T-statistics in parentheses. 
Table 6. Backache, sciatica, disk prolapse and pain lasting more than one day - NCDS9 at 55 (OLS).

\begin{tabular}{|c|c|c|c|c|}
\hline Chronic pain at 44 & $.2363(23.00)$ & $.1582(13.85)$ & $.2369(22.01)$ & .1604 (13.37) \\
\hline Short pain at 44 & $.1036(7.05)$ & $.0803(5.21)$ & $.1129(7.29)$ & $.0865(5.33)$ \\
\hline Male & $.0067(0.64)$ & $.0003(0.03)$ & $-.0099(0.92)$ & $-.0033(0.29)$ \\
\hline Aches \& pains at 16 & & & .1302 (2.87) & $.0760(1.60)$ \\
\hline Pain very mild at 50 & & $.0486(3.76)$ & & $.0517(3.82)$ \\
\hline Pain mild at 50 & & .1135 (7.34) & & $.1128(6.97)$ \\
\hline Pain moderate at 50 & & $.2417(15.17)$ & & $.2354(14.00)$ \\
\hline Pain severe at 50 & & $.2933(12.21)$ & & $.2885(11.50)$ \\
\hline Pain very severe at 50 & & $.3700(7.80)$ & & $.3193(6.37)$ \\
\hline PT employee & $.0074(0.47)$ & $.0100(0.61)$ & $.0109(0.66)$ & $.0123(0.71)$ \\
\hline FT self-employed & $.0165(0.91)$ & $.0283(1.52)$ & $.0192(1.01)$ & .0318 (1.63) \\
\hline PT self-employed & $-.0490(1.78)$ & $-.0413(1.44)$ & $-.0475(1.66)$ & -.0418 (1.39) \\
\hline Unemployed & $-.0030(0.08)$ & $-.0309(0.72)$ & $.0158(0.38)$ & $-.0150(0.33)$ \\
\hline FT education & $.2381(1.70)$ & $.2838(1.96)$ & $.2377(1.70)$ & $.2863(1.97)$ \\
\hline Temporarily sick/disabled & $.1751(1.25)$ & $.2222(1.53)$ & $.2946(1.85)$ & $.2638(1.69)$ \\
\hline Permanently sick/disabled & $.0767(2.62)$ & $.0334(1.05)$ & $.0816(2.63)$ & $.0389(1.17)$ \\
\hline Looking after home & $.0102(0.43)$ & $.0277(1.10)$ & $-.0006(0.02)$ & $.0221(0.84)$ \\
\hline Wholly retired & $-.0125(0.63)$ & $-.0042(0.21)$ & $-.0092(0.45)$ & $.0006(0.03)$ \\
\hline GCSE D-E & $-.2358(1.12)$ & $-.1440(0.50)$ & $-.2341(1.11)$ & $-.1530(0.53)$ \\
\hline Other Scottish Quals & -.0162 (0.89) & $.0085(0.44)$ & $-.0197(1.02)$ & $.0037(0.18)$ \\
\hline GCSE A-C & $-.0520(3.34)$ & $-.0298(1.82)$ & $-.0518(3.16)$ & $-.0357(2.07)$ \\
\hline 2/AS Levels or 1 A Level & $-.0601(0.91)$ & $-.0082(0.12)$ & -.0886 (1.29) & $-.0621(0.85)$ \\
\hline 2+ A Levels & $-.0413(1.95)$ & $-.0163(0.74)$ & $-.0509(2.27)$ & $-.0316(1.35)$ \\
\hline Diploma & $-.0364(1.50)$ & $-.0227(0.90)$ & $-.0245(0.97)$ & $-.0159(0.60)$ \\
\hline Degree & $-.0655(3.66)$ & $-.0330(1.76)$ & $-.0621(3.30)$ & $-.0347(1.76)$ \\
\hline Higher Degree & $-.0863(3.24)$ & $-.0588(2.14)$ & $-.0820(2.93)$ & $-.0603(2.09)$ \\
\hline \multicolumn{5}{|l|}{ Father's social class at 0} \\
\hline Semi-skilled & $-.0421(2.31)$ & $-.0446(2.34)$ & $-.0386(2.04)$ & $-.0432(2.17)$ \\
\hline Unskilled worker & .0217 (1.09) & $.0165(0.78)$ & .0225 (1.09) & $.0081(0.37)$ \\
\hline Armed forces & $.0124(0.44)$ & $.0178(0.61)$ & $.0128(0.44)$ & $.0159(0.52)$ \\
\hline Admin, prof, manager & $.0037(0.23)$ & $.0013(0.08)$ & $-.0064(0.38)$ & $-.0067(0.38)$ \\
\hline Shopkeepers & -.0416 (1.29) & $-.0231(0.71)$ & $-.0358(1.07)$ & $-.0184(0.54)$ \\
\hline Clerical workers & $-.0436(1.92)$ & $-.0388(1.64)$ & $-.0407(1.70)$ & $-.0345(1.39)$ \\
\hline Shop assistants & $.0136(0.59)$ & $.0130(0.53)$ & $-.0070(0.29)$ & $-.0090(0.35)$ \\
\hline Personal service & $-.0651(1.44)$ & $-.0409(0.83)$ & $-.1012(2.06)$ & $-.0622(1.16)$ \\
\hline Foremen & $-.1145(3.36)$ & $-.0857(2.37)$ & $-.1138(3.21)$ & $-.0861(2.28)$ \\
\hline Farmers & $.0124(0.36)$ & $.0306(0.84)$ & $.0345(0.92)$ & $.0472(1.21)$ \\
\hline Farm workers & $.0125(0.48)$ & $.0092(0.34)$ & $.0092(0.34)$ & $.0096(0.34)$ \\
\hline Higher admin etc. & $-.0194(0.86)$ & $-.0290(1.24)$ & $-.0156(0.66)$ & $-.0315(1.28)$ \\
\hline Single, no husband & $.0484(1.39)$ & $.0794(2.16)$ & $.0505(1.36)$ & $.0814(2.08)$ \\
\hline Doing all right & $.0201(1.74)$ & $.0046(0.39)$ & $.0208(1.71)$ & $.0075(0.60)$ \\
\hline Just about getting by & .0435 (3.18) & $.0114(0.79)$ & $.0411(2.88)$ & $.0110(0.74)$ \\
\hline Finding it quite difficult & .0807 (3.83) & $.0467(2.10)$ & .0812 (3.65) & $.0524(2.23)$ \\
\hline Finding it very difficult & $.2052(7.72)$ & $.1698(5.88)$ & $.2039(7.41)$ & $.1740(5.86)$ \\
\hline Region at 55 & Yes & Yes & Yes & Yes \\
\hline Father's social class at 0 & Yes & Yes & Yes & Yes \\
\hline Constant & .1404 & .0545 & .1461 & .0531 \\
\hline Adjusted $\mathrm{R}^{2}$ & .0943 & .1290 & .0910 & .1271 \\
\hline $\mathrm{N}$ & 7,875 & 6904 & 7,191 & \\
\hline
\end{tabular}

Notes: education, labor force status and financial situation in NCDS9 at age 55. Excluded pain at $50=$ none. Pain at age 16 from NCDS3 (n2317) student 'often complains of aches or pains? yes/no reported by teacher/school mean=.016. Mean of dependent variable 25.7\%. Excluded: ft employee; no qualifications, skilled worker and living comfortably 
Table 7. Depression, emotional and psychiatric problems since last interview NCDS9 at 55.

\begin{tabular}{|c|c|c|c|c|}
\hline Chronic pain at 44 & 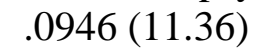 & $.0309(3.86)$ & $.0337(4.09)$ & $.0241(2.75)$ \\
\hline Short pain at 44 & 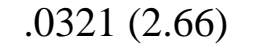 & .0060 (0.53) & . $0044(0.38)$ & $.0036(0.31)$ \\
\hline Male & $-.0677(8.73)$ & $-.0300(3.72)$ & $-.0320(3.88)$ & $-.0296(3.51)$ \\
\hline \multicolumn{2}{|l|}{ Fatigue score at 44} & $.0157(4.77)$ & .0167 (4.95) & $.0170(4.94)$ \\
\hline \multicolumn{2}{|l|}{ Concentration score at 44} & $.0230(3.45)$ & $.0203(2.96)$ & $.0115(1.65)$ \\
\hline \multicolumn{2}{|l|}{ Sleep score at 44} & $.0139(3.75)$ & .0143 (3.77) & $.0136(3.53)$ \\
\hline \multicolumn{2}{|l|}{ Irritability score at 44} & $.0135(3.00)$ & $.0148(3.21)$ & $.0169(3.60)$ \\
\hline \multicolumn{2}{|c|}{ Depressive ideas score at 44} & $.0228(3.76)$ & . 0245 (3.93) & $.0251(3.93)$ \\
\hline \multicolumn{2}{|l|}{ Anxiety score at 44} & $.0133(2.18)$ & $.0182(2.88)$ & $.0173(2.67)$ \\
\hline \multicolumn{2}{|l|}{ Phobias score at 44} & $.0406(5.62)$ & $.0358(4.77)$ & $.0382(4.96)$ \\
\hline \multicolumn{2}{|l|}{ Panic score at 44} & $.0294(2.29)$ & .0289 (2.22) & $.0295(2.26)$ \\
\hline \multicolumn{2}{|l|}{ Doing all right at 55} & $.0262(2.96)$ & $.0256(2.82)$ & $.0236(2.57)$ \\
\hline \multicolumn{2}{|l|}{ Just about getting by at 55} & $.0705(6.74)$ & $.0699(6.52)$ & $.0732(6.69)$ \\
\hline \multicolumn{2}{|c|}{ Finding it quite difficult at 55} & 1026 (6.34) & .1006 (6.05) & $.0895(5.28)$ \\
\hline \multicolumn{2}{|c|}{ Finding it very difficult at 55} & 2334 (11.43) & $2106(9.88)$ & $.2032(9.22)$ \\
\hline \multicolumn{2}{|l|}{ Pain very mild at 50} & & & $.0039(0.38)$ \\
\hline \multicolumn{2}{|l|}{ Pain mild at 50} & & & $.0190(1.56)$ \\
\hline \multicolumn{2}{|l|}{ Pain moderate at 50) } & & & $.0478(3.79)$ \\
\hline \multicolumn{2}{|l|}{ Pain severe at 50} & & & $.0258(1.34)$ \\
\hline \multicolumn{2}{|l|}{ Pain very severe at 50} & & & $.1254(3.23)$ \\
\hline Personal controls & No & Yes & Yes & Yes \\
\hline Father's social class at 0 & No & No & Yes & Yes \\
\hline Constant & .1388 & .1936 & .2179 & .1990 \\
\hline Adjusted $\mathrm{R}^{2}$ & .0242 & .1422 & .1713 & .1812 \\
\hline $\mathrm{N}$ & 8,266 & 8,246 & 7,849 & 7,391 \\
\hline
\end{tabular}

Notes: personal controls are region, marital and labor force status and education in NCDS9 at age 55. Excluded category personal assessment of financial situation - living comfortably and pain at 42 none. Financial situation at age 55. Mean depression 15.2\% - mean chronic pain at 44 depressed $=54.5 \%$ v $37.6 \%$ not depressed. All mental health scores at age 42 Means

Fatigue score at $44 \quad .831$

Concentration score at $44 \quad .247$

Sleep score at $44 \quad .731$

Irritability score at $44 \quad .573$

Depressive ideas score at $44 \quad .235$

Anxiety score at $44 \quad .275$

Phobias score at $44 \quad .180$

Panic score at $44 \quad .044$

Total summary score at $44 \quad 3.40$ 
Table 8. General health in NCDS9 at 55 (OLS)

Chronic pain at 44

Short pain at 44

Male

Mental Health score at 44

Pain very mild at 50

Pain mild at 50

Pain moderate at 50

Pain severe at 50

Pain very severe at 50

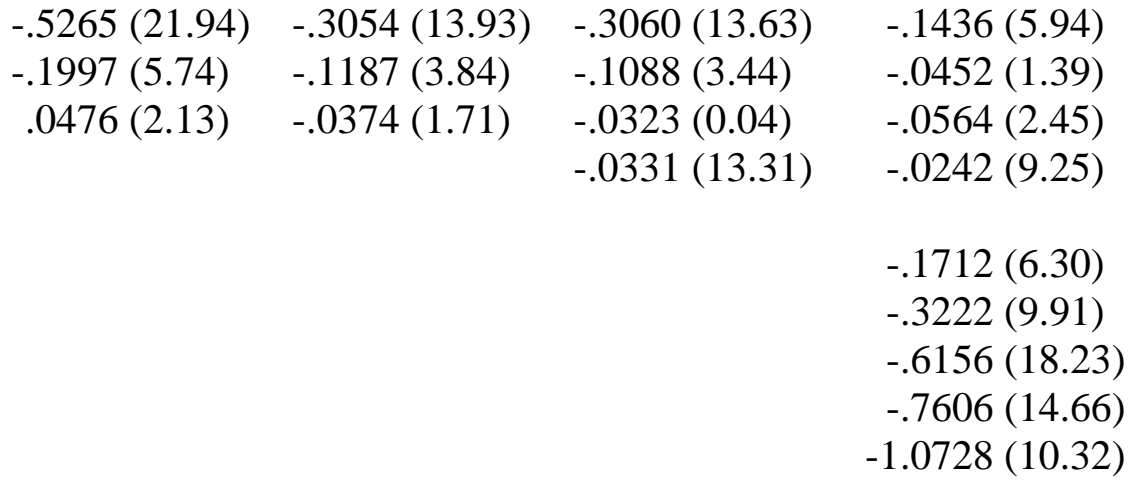

Personal controls

Father's social class

No

No

Yes

No

Yes

Yes

Yes

Yes

\subsection{4}

.3186

6.895

$\begin{array}{lcccc}\text { Constant } & 3.6005 & 3.7662 & 3.7681 & 3.9844 \\ & & & & \\ \text { Adjusted } \mathrm{R}^{2} & .0575 & .2690 & .2720 & .3186 \\ \mathrm{~N} & 8,286 & 8,266 & 7,885 & 6.895\end{array}$

Notes: all equations include region at age 55. Personal controls are financial situation, labor force status and education in NCDS9 at age 55. Mean health score=3.40. 
Table 9. Paid Work or FT education in NCDS9 at 55.

Chronic pain at $44 \quad-0831(9.06)$

Short pain at $44 \quad-.0272(2.04) \quad-.0283(2.14)$

$$
\begin{array}{lll}
-.0727(7.74) & -.0319(3.05) & -.0213(2.42) \\
-.0270(1.99) & -.0164(1.16) & -.0156(1.21) \\
.0710(8.05) & .0645(6.98) & .0103(1.10)
\end{array}
$$

Male $.0713(8.34) \quad .0726(8.47)$

Pain very mild at 50

Pain mild at 50

Pain moderate at 50

Pain severe at 50

Pain very severe at 50

Labor force status age 46

Personal controls

No

Father's social class

No

No
Yes

No
Yes

No

No

$.0016(0.14)$

$-.0098(0.69)$

$-.0813(5.58)$

-.2162 (9.87)

$-.5199(12.05)$

$\begin{array}{ll}\text { Constant } & .8083 \\ \text { Adjusted } \mathrm{R}^{2} & .0195 \\ \mathrm{~N} & 8,350\end{array}$

.6229
.0365
8,350

No
Yes
Yes
.6170
.0375
7,942

$\begin{array}{rr}\text { No } & \text { Yes } \\ \text { Yes } & \text { Yes } \\ \text { Yes } & \text { Yes }\end{array}$

Notes: all equations include controls for region at age 55. Personal controls are marital status and education in NCDS9 at age 55 
Table 10. Attitudes in NCDS9 at age 55.

Full of energy these days

$\begin{array}{lcc}\text { Chronic pain at 44 } & -.1543(7.96) & -.0839(4.08) \\ \text { Short pain at 44 } & -.0367(1.34) & -.0120(0.43) \\ \text { Male } & .0043(0.22) & .0016(0.08) \\ & & \\ \text { Mental Health score at } 44 & -.0332(15.53) & .0279(12.66) \\ & & -.1244(5.17) \\ \text { Pain very mild at 50 } & & -.1806(6.27) \\ \text { Pain mild at 50 } & & -.3349(11.22) \\ \text { Pain moderate at 50) } & & -.3463(7.56) \\ \text { Pain severe at 50 } & & -.6324(7.01) \\ \text { Pain very severe at 50 } & & \text { Yes } \\ \text { Personal controls } & & 3.3549 \\ \text { Constant } & 3.2633 & .1884 \\ \text { Adjusted } \mathrm{R}^{2} & & 7,770 \\ \mathrm{~N} & 8,1695 & \end{array}$

Life is full of opportunities $-.0952(5.08) \quad-.0581(2.89)$ $-.0181(0.68) \quad .0197(0.73)$ $-.0539(2.86) \quad-.0481(2.48)$

$-.0179(8.68) \quad-.0155(7.19)$

$-.0675(2.87)$

$-.0969(3.45)$

$-.1731(5.95)$

$-.0994(2.22)$

$-.1153(5.56)$

Yes

3.2310
.1586
8,236

Future looks good for me

$\begin{array}{cc}-.0748(4.38) & -.0433(2.36) \\ -.0095(0.08) & .0056(0.23) \\ -.0953(5.55) & -.0967(5.48) \\ -.0208(11.01) & -.0184(9.36) \\ & -.0525(2.45) \\ & -.0280(1.10) \\ & -.1181(4.45) \\ & -.1028(2.52) \\ & -.0744(0.92) \\ \text { Yes } & \text { Yes } \\ 3.6051 & 3.6182 \\ .0776 & .2456 \\ 8,221 & 7,742\end{array}$

Coded $4=$ often $3=$ sometimes $2=$ not often $1=$ never

Notes: personal controls are region; marital, financial situation and education dummies in NCDS9 at age 55. Excluded category personal assessment of financial situation - living comfortably. Financial situation and ill-being score at age 46.

Mean energy 2.94; life full=3.08 and future 3.24. 
Table 11. Life satisfaction and Malaise Scores in NCDS7 at 46 and NCDS8 at 50 (OLS).

\begin{tabular}{|c|c|c|c|c|c|c|}
\hline \multicolumn{2}{|c|}{ Life satisfaction at 46} & \multicolumn{2}{|c|}{ Life satisfaction at 50} & \multicolumn{3}{|c|}{ Malaise score at 50} \\
\hline Chronic pain at 44 & $-.3427(9.70)$ & $-.4862(10.95)$ & $-.2118(5.41)$ & $.7658(16.70)$ & $.6270(13.94)$ & .5074 (11.39) \\
\hline Short pain at 44 & $-.2019(3.92)$ & $-.1870(2.92)$ & $-.0558(1.01)$ & $.3072(4.63)$ & $.2981(4.64)$ & $.1932(3.06)$ \\
\hline Male & $-.1419(4.32)$ & $.0225(0.55)$ & $.0256(0.63)$ & $-.5806(13.63)$ & $-.5070(10.93)$ & $-.5309(11.57)$ \\
\hline $\begin{array}{l}\text { Aches \& pains at } 16 \\
\text { Life satisfaction at } 46\end{array}$ & $-.3272(2.23)$ & $-.3864(2.11)$ & $\begin{array}{l}-.2109(1.30) \\
.6259(48.66)\end{array}$ & $.8338(4.42)$ & $.5252(2.85)$ & $\begin{array}{l}.5320(2.89) \\
-.3479(23.76)\end{array}$ \\
\hline Region & Yes & Yes & Yes & Yes & Yes & Yes \\
\hline Father's social class at 0 & Yes & Yes & Yes & Yes & Yes & Yes \\
\hline Personal controls & No & Yes & Yes & No & Yes & Yes \\
\hline Constant & 7.8048 & 3.3549 & 3.2310 & 1.4338 & 1.4250 & 4.1210 \\
\hline Adjusted $\mathrm{R}^{2}$ & .1695 & .1884 & .2862 & .0654 & .1253 & .1854 \\
\hline $\mathrm{N}$ & 7,810 & 7,770 & 7,038 & 7,436 & 7,436 & 7,032 \\
\hline
\end{tabular}

Notes: personal controls in columns 2 and 3 are labor force status and education dummies in NCDS8 at age 50. Malaise score from 09 mean $=1.488$

n7life mean=7.57 n8 life mean=7.28 
Table 12. Hours of sleep and short sleep in NCDS8 at 50 and problems falling asleep at 44.

\begin{tabular}{|c|c|c|c|c|c|c|}
\hline & \multicolumn{2}{|c|}{ Hours of sleep } & \multicolumn{2}{|c|}{ Short sleep ( $<7 \mathrm{hrs})$} & \multicolumn{2}{|c|}{ Problems falling asleep at 44} \\
\hline Chronic pain at 44 & $-.2277(8.10)$ & $-.2102(6.90)$ & .1037 (9.09) & $.0814(6.58)$ & .1532 (13.57) & $.1519(12.64)$ \\
\hline Short pain at 44 & -.1085 (2.67) & $-.1050(2.42)$ & $.0568(3.44)$ & $.0525(2.98)$ & $.0368(2.24)$ & $.0355(2.03)$ \\
\hline Male & $-.0871(3.33)$ & $-.0521(1.66)$ & $.0134(1.26)$ & $.0019(0.15)$ & $-.0676(6.44)$ & $-.0750(6.64)$ \\
\hline Aches \& pains at 16 & & $-.2806(2.23)$ & & $.0987(1.91)$ & & $-.0334(0.70)$ \\
\hline Region & Yes & Yes & Yes & Yes & Yes & Yes \\
\hline Father's social class at 0 & No & Yes & No & Yes & Yes & Yes \\
\hline Personal controls & No & Yes & No & Yes & No & No \\
\hline Constant & 6.9391 & .3462 & .3128 & .3496 & .3577 & .3677 \\
\hline Adjusted $\mathrm{R}^{2}$ & .0102 & .0247 & .0112 & .0282 & .0305 & .0318 \\
\hline $\mathrm{N}$ & 7873 & 6859 & 7755 & 6756 & 8171 & 7,228 \\
\hline
\end{tabular}

Notes: personal controls are labor force status and education dummies in NCDS8 at age 50. Short sleep is versus normal sleep of 7-9 hours so those with $>=10$ hrs are dropped in columns3 and 4 . Mean sleep hours=6.91 

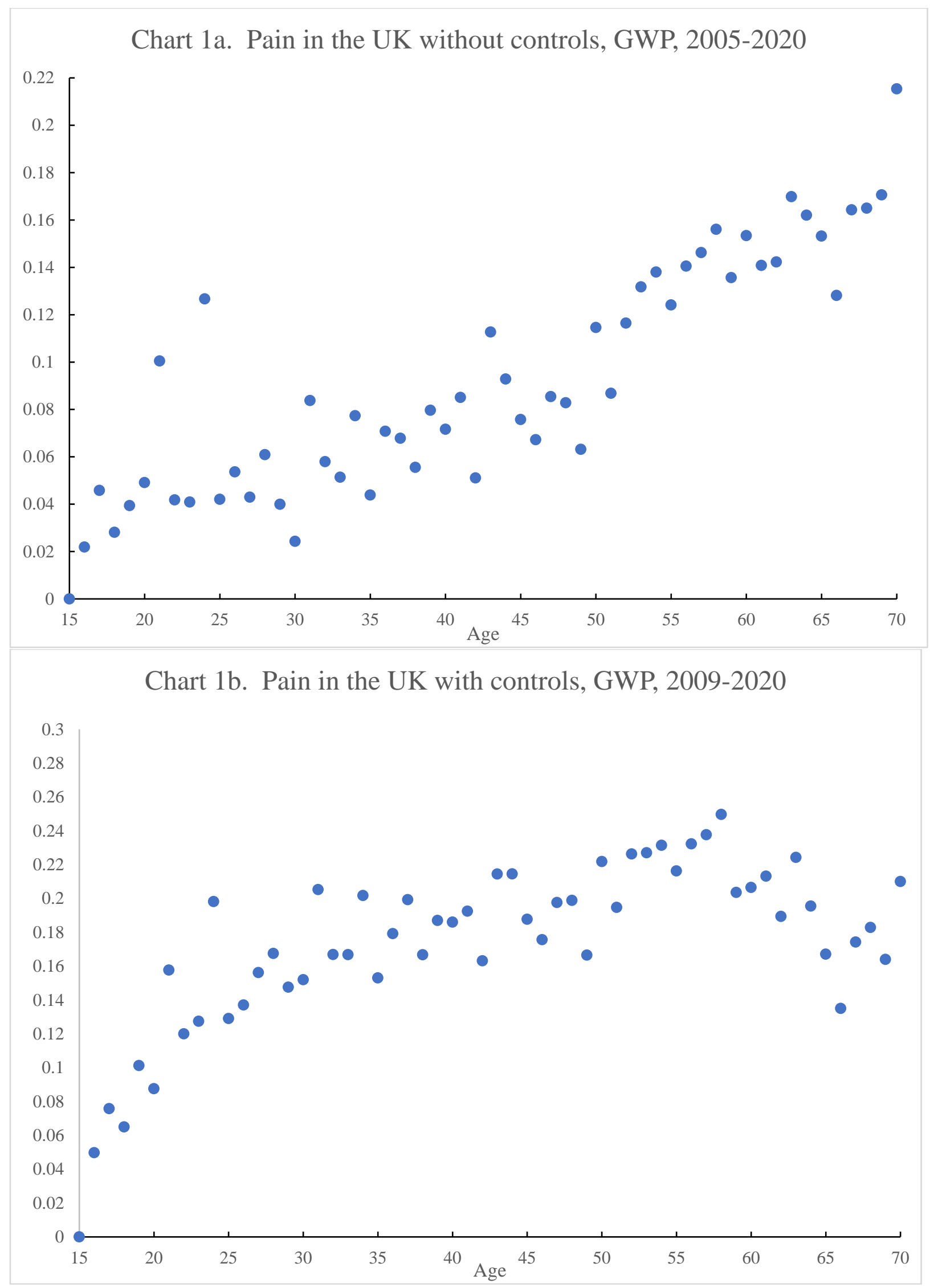
Appendix. Pain questions from 2002-2004 Biomedical study

\section{E. PAIN}

E1 During the past month, have you had any ache or pain which has lasted for one day or longer? (Please do not include pain occurring only during menstrual periods or during the course of a feverish illness such as 'flu.)

Tick one box

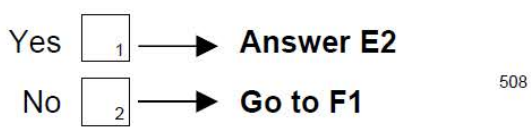

E2 Thinking about this pain, have you been aware of it for more than 3 months?

\section{Tick one box}

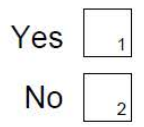

E3 Below you will find four diagrams of the body.

Please shade in all the places where you felt or feel the aches and pains.

RIGHT

BACK

FRONT

LEFT
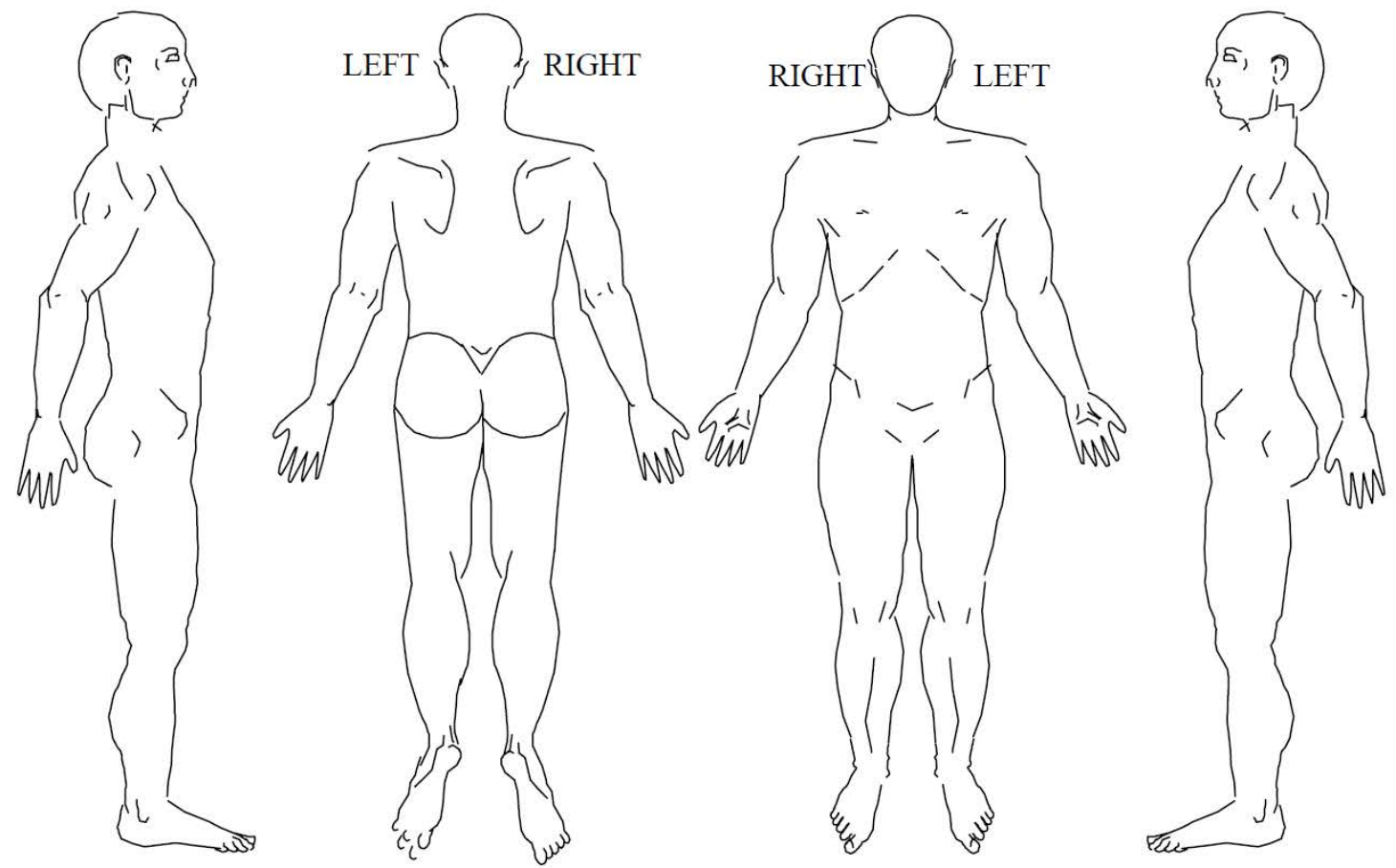